Research Article

\title{
Comparative Study of Lightweight Cementitious Composite Reinforced with Different Fibre Types and the Effect of Silane-Based Admixture
}

\author{
Geok Wen Leong $\mathbb{D}^{D}$, Hui Loo Chua, Kim Hung Mo $\mathbb{D}$, Zainah Ibrahim, and Zhi Pin Loh \\ Department of Civil Engineering, Faculty of Engineering, Universiti Malaya, Kuala Lumpur 50603, Malaysia \\ Correspondence should be addressed to Geok Wen Leong; geokwen@um.edu.my
}

Received 8 June 2021; Revised 5 October 2021; Accepted 13 November 2021; Published 2 December 2021

Academic Editor: Quoc-Bao Bui

Copyright (c) 2021 Geok Wen Leong et al. This is an open access article distributed under the Creative Commons Attribution License, which permits unrestricted use, distribution, and reproduction in any medium, provided the original work is properly cited.

\begin{abstract}
This study aims to develop a type of fine-grained lightweight concrete, also known as lightweight cementitious composite (LCC), containing perlite microsphere (PM) and fibres with enhanced impermeability. The effect of polypropylene (PP), polyvinyl alcohol (PVA), and basalt fibres on the fresh and hardened properties of LCC was investigated. Besides, silane-based water repellent admixture was incorporated to reduce the water absorption and enhance the hydrophobicity of LCC. The dry densities of LCC developed were in the range of $912-985 \mathrm{~kg} / \mathrm{m}^{3}$. PP fibres have lesser influence on the strengths of LCC. However, PVA fibres enhanced the strength of LCC by up to $35.2 \%$ and $28 \%$ in the compressive strength and flexural strength, respectively, while the basalt fibres increased both strengths up to $30.1 \%$ and $43.5 \%$, respectively. By considering the overall performance, LCC with $0.5 \%$ PVA fibres has achieved a good balance in workability and strength. Additionally, silane-based water repellent admixture had an excellent effect in reducing the water absorption and improving the hydrophobicity of LCC. By incorporating $1 \%$ of silane-based water repellent admixture, the LCC with $0.5 \%$ PVA fibres obtained water-resistant properties with the softening coefficient of 0.85 and water contact angle of $128.2^{\circ}$. In conclusion, a combination of PVA-LCC with $1 \%$ waterproofing admixture showed the best performance in terms of mechanical strength as well as hydrophobic properties and had the potential to be used in the fabrication of concrete façade.
\end{abstract}

\section{Introduction}

Concrete and cement-based materials are commonly used to fabricate façade panels because of their durability and versatility. With the use of lightweight concrete, the lifting efficiency of the panels can be improved, which shortens the installation process. According to BS EN 206, the oven-dry density of lightweight concrete is in the range of $800 \mathrm{~kg} / \mathrm{m}^{3}$ to $2000 \mathrm{~kg} / \mathrm{m}^{3}$. The low density of lightweight concrete can be achieved by incorporating lightweight aggregates. Conventional lightweight aggregates such as expanded perlite also possess low thermal conductivity, thus providing thermal insulation to the building [1]. However, the incorporation of expanded perlite reduces the compressive strength and increases the water absorption of concrete due to its porous nature [2]. Although façade panels are nonstructural elements that are only subjected to self-weight and wind load, the increase in water absorption of lightweight concrete will increase the self-weight of the panels during the wet season. This drawback can be minimised by utilising microsized expanded perlite, namely, perlite microsphere (PM).

PM has a closed pore structure which allows it to achieve lower water absorption than conventional expanded perlite. The typical water absorption of expanded perlite is between 30 and $71 \%[1,3,4]$. On the other hand, the water repellence of PM is $10 \%$ higher than the conventional expanded perlite [5]. In addition, the reduction in particle size of expanded perlite can increase the strength of PM [6, 7]. So, PM is less vulnerable to shearing force. Previously, the authors have developed a lightweight cementitious composite (LCC) using PM. LCC is a type of fine-grained lightweight 
aggregate concrete with a high specific strength. The developed LCC achieved a 28-day compressive strength of $23.7 \mathrm{MPa}$ with the dry density of $979 \mathrm{~kg} / \mathrm{m}^{3}$ [8]. Considering the lower strength requirement for facade panel, the LCC mix could be altered to suit this application.

Lightweight cement-based material is usually more brittle than normal-weight concrete $[2,9]$. The addition of fibres to the lightweight cementitious composite can be a promising solution to overcome the drawback of brittleness. The existence of fibres in cementitious composite delays and mitigates the propagation of microcracks and macrocracks [10]. Many researchers have manifested the effectiveness of using fibrous material to improve the hardened properties of the concrete [11-13]. The distribution, orientation, geometry, and volumetric proportion of fibres in the matrix are essential parameters in affecting the mechanical properties of composites. Therefore, it is crucial to determine the suitable type and optimal dosage of fibres for LCC made of PM while maintaining the low density of LCC.

Furthermore, enhancing the hydrophobic properties of LCC can be an added value since one of the main challenges encountered in façade wall application is surface staining due to weathering [14]. Hydrophobic properties can be achieved by using a hydrophobic agent during the mixing stage $[15,16]$ or water repellent coating [17]. However, the surface coating method can become more vulnerable under UV radiation [18]. Therefore, from the practical point of view, mixing the hydrophobic agent directly in LCC is preferable because if the surface of LCC is destroyed, the newly exposed part of the LCC can still exhibit hydrophobicity. Therefore, in this research, a silane-based water repellent admixture was added in LCC during mixing.

In short, this study aims to develop LCC containing PM and fibres with enhanced impermeability. The effect of polypropylene (PP), polyvinyl alcohol (PVA), and basalt fibres on the workability and mechanical strength of LCC was evaluated. Besides that, silane-based water repellent admixture was incorporated to reduce the water absorption and enhance the hydrophobicity of LCC. This study would be useful for the application of LCC as a façade panel.

\section{Materials and Methods}

2.1. Materials. CEM I Ordinary Portland Cement (OPC) of class $42.5 \mathrm{~N}$ was used in this study. Silica fume (SF) and fly ash (FA), fulfilling EN 13263-1 and EN 450-1, were used as supplementary cementing materials to improve the properties of the composites. PM with a bulk density of $700 \mathrm{~kg} / \mathrm{m}^{3}$ and an average particle size of $200 \mu \mathrm{m}$ was used as lightweight aggregate to produce LCC (Figure 1). PP, PVA, and basalt fibres used in this study are shown in Figure 2. The properties of fibres provided by manufacturer are presented in Table 1. To produce LCC with adequate consistency and improved cohesiveness of the mixture, polycarboxylate ether-based superplasticiser (SP) and styrene butadiene rubber (SBR) were used in all mixes. Additionally, silane-based water repellent admixture was incorporated in the selected mix, and the hydrophobic properties of LCC were investigated.
2.2. Mix Proportioning and Sample Preparation. Ten mixtures with a varying volume of PP, PVA, and basalt fibres were prepared. Besides the control mix (PM-0), the LCCs were categorised into 3 groups (LCC-PP, LCC-PVA, and LCC-basalt) based on the respective fibre type. The volume fraction of each type of fibre varied between $0 \%, 0.125 \%, 0.25 \%$, and $0.50 \%$. Additionally, two mixes of LCC with $0.50 \%$ PVA fibres were added with $1 \%$ and $2 \%$ of silane-based admixture. The mixture proportion of LCCs is tabulated in Table 2. All other parameters such as binder content $\left(600 \mathrm{~kg} / \mathrm{m}^{3}\right)$ and the water/binder ratio, dosage of SP, and SBR were kept constant in all mixtures.

The mixing process of LCC started with dry mixing of binders and PM for one minute. It was then followed by adding water and chemical admixtures while continuing mixing for another two minutes. Next, the fibres were gradually dispersed in the mix, and the mixing process continued until a homogeneous mixture was obtained. A portion of the fresh LCC was used to conduct the flow table test, while the rest was cast into prelubricated moulds. After compaction, the specimens were covered by plastic sheets to avoid loss of moisture. From each batch, six $50 \mathrm{~mm}$ cubes (for compressive strength) and three prisms with a dimension of $40 \mathrm{~mm} \times 40 \mathrm{~mm} \times 160 \mathrm{~mm}$ (for flexural strength test) were cast. For LCC with silane-based admixture, additional $50 \mathrm{~mm}$ cubes (water absorption test and water saturated compressive strength test) and LCC tiles with a dimension of $70 \mathrm{~mm} \times 75 \mathrm{~mm} \times 16 \mathrm{~mm}$ (contact angle test) were prepared. All the specimens were demoulded 24 hours after casting, and the hardened LCC specimens were air-cured in laboratory condition until the age of testing.

2.3. Test Methods. The flow table test was carried out following ASTM C1437. The compressive strength test was carried out at the age of 7 days and 28 days and in accordance with ASTM C109. The flexural strength test was conducted via 3 -point bending. The machine used in the bending test is INSTRON displacement-controlled testing machine with a load capacity of $100 \mathrm{kN}$. Besides that, the water absorption of specimens with silane-based water repellent admixture after immersion for 30 mins and 48 hours was determined. The contact angle test was carried out to determine the surface hydrophobicity of LCC which was incorporated with silanebased admixture. The contact angle was measured using an optical contact angle measuring system, OCA 15EC, with Spinocerebellar Ataxia Type 20 (SCA20) software (Figure 3) after placing a distilled water droplet on the specimen surface.

\section{Results and Discussion}

3.1. Workability. Figure 4 shows the workability of fresh LCC with varying types and dosages of fibres. Based on the results, an increase in fibre dosage decreased the workability of LCC regardless the type of fibre. Similar findings were reported by Jiang et al. [19] and Loh et al. [20]. With the inclusion of $0.50 \%$ of PP, PVA, and basalt fibre, the workability of the control mix decreased by $24.6 \%, 32.5 \%$, and $56.9 \%$, respectively. Under the condition of fixed binder content and dosage of chemical admixture, the surface area 


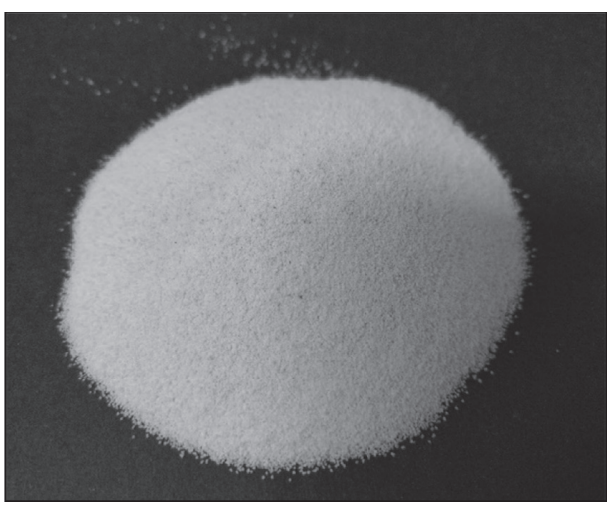

(a)

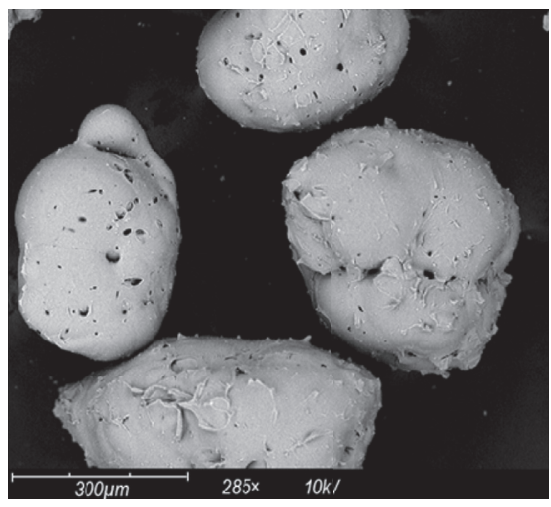

(b)

FIgure 1: (a) Physical appearance of PM; (b) SEM image of PM.

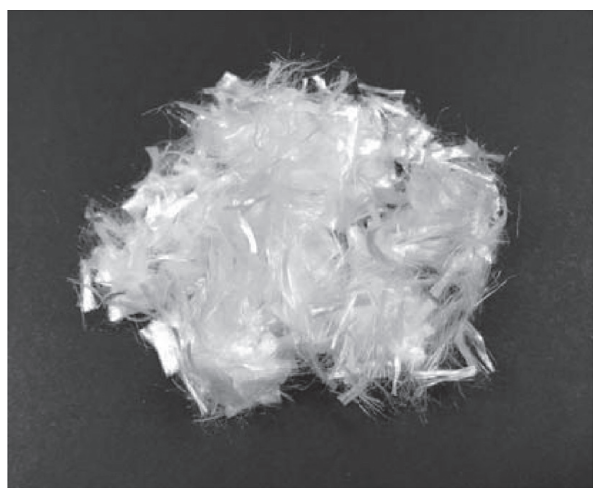

(a)

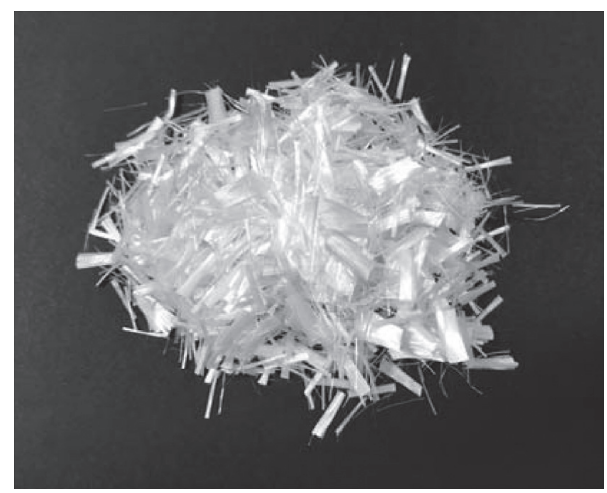

(b)

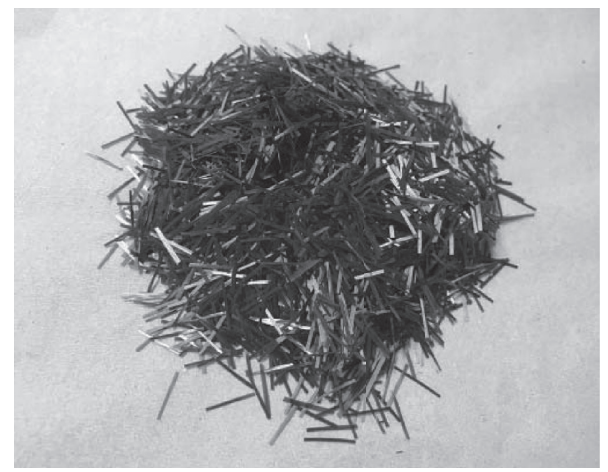

(c)

Figure 2: (a) PP fibres; (b) PVA fibres; (c) basalt fibres.

and stiffness of fibres are the factors affecting the workability of fibre-reinforced mortar. Since basalt fibre has the highest aspect ratio and modulus of elasticity among the fibres used, this led to the greatest reduction in workability of the LCC.

3.2. Density. The density of LCC developed in this study was in the range of 912 to $985 \mathrm{~kg} / \mathrm{m}^{3}$. The effect of fibres on LCC density was less significant in this study due to the low incorporation level of fibres, which was less than $1 \%$. The highest percentage difference was observed with $0.50 \%$ PVA fibres, where the density of the control mix increased by $8 \%$. A similar trend was observed in both LCC-PP and LCC-
PVA. The density increased with a higher dosage of fibres. However, in the case of basalt fibres, the density of LCC with $0.50 \%$ basalt fibres $(\mathrm{PM}+0.50 \mathrm{~B})$ was lower than that of LCC with $0.25 \%$ basalt fibres $(\mathrm{PM}+0.25 \mathrm{~B})$. In fact, this correlates with the low workability of $\mathrm{PM}+0.50 \mathrm{~B}$, which resulted in poor compaction and low density.

\subsection{Compressive Strength}

3.3.1. Effects of Fibres on Compressive Strength. The compressive strength of LCCs is tabulated in Table 3. Early strength development of LCC was observed by 
TABle 1: Properties of fibres.

\begin{tabular}{lccc}
\hline Properties & \multicolumn{2}{c}{ Types of fibre } \\
& PP & PVA & 12 \\
Length $(\mathrm{mm})$ & 12 & 40 & 12 \\
Diameter $(\mu \mathrm{m})$ & 50 & 1.29 & 2.67 \\
Density $\left(\mathrm{g} / \mathrm{cm}^{3}\right)$ & 0.90 & 1600 & $4150-4800$ \\
Tensile strength $(\mathrm{MPa})$ & $350-500$ & 41 & $100-110$ \\
Modulus of elasticity $(\mathrm{GPa})$ & $3.5-3.9$ & 300 & 1083 \\
Aspect ratio (length/diameter) & 240 & & \\
\hline
\end{tabular}

TABLE 2: Mixture proportions of LCC (by weight of binder).

\begin{tabular}{|c|c|c|c|c|c|c|c|c|c|c|c|}
\hline \multirow{2}{*}{ Mix ID } & \multicolumn{3}{|c|}{ Binder } & \multirow{2}{*}{ Water/binder ratio } & \multirow{2}{*}{ PM } & \multicolumn{3}{|c|}{${ }^{*}$ Fibre (\%) } & \multicolumn{3}{|c|}{${ }^{* * *}$ Chemical admixture (\%) } \\
\hline & OPC & FA & SF & & & PP & PVA & Basalt & SBR & SP & Water repellent \\
\hline PM-0 (control mix) & & & & & & - & - & - & & & - \\
\hline $\mathrm{PM}+0.125 \mathrm{PP}$ & & & & & & 0.125 & - & - & & & - \\
\hline $\mathrm{PM}+0.25 \mathrm{PP}$ & & & & & & 0.250 & - & - & & & - \\
\hline $\mathrm{PM}+0.50 \mathrm{PP}$ & & & & & & 0.500 & - & - & & & - \\
\hline $\mathrm{PM}+0.125 \mathrm{PVA}$ & & & & & & - & 0.125 & - & & & - \\
\hline $\mathrm{PM}+0.25 \mathrm{PVA}$ & & & & & & - & 0.250 & - & & & - \\
\hline $\mathrm{PM}+0.50 \mathrm{PVA}$ & 0.78 & 0.17 & 0.05 & 0.35 & 0.42 & - & 0.500 & - & 10.0 & 1.2 & - \\
\hline $\mathrm{PM}+0.125 \mathrm{~B}$ & & & & & & - & - & 0.125 & & & - \\
\hline $\mathrm{PM}+0.25 \mathrm{~B}$ & & & & & & - & - & 0.250 & & & - \\
\hline $\mathrm{PM}+0.50 \mathrm{~B}$ & & & & & & - & - & 0.500 & & & - \\
\hline $\mathrm{W} 1 \mathrm{PM}+0.50 \mathrm{PVA}$ & & & & & & - & 0.500 & - & & & 1.0 \\
\hline $\mathrm{W} 2 \mathrm{PM}+0.50 \mathrm{PVA}$ & & & & & & - & 0.500 & - & & & 2.0 \\
\hline
\end{tabular}

Notes: * means by volume of aggregate; ${ }^{* *}$ means by weight of binder.

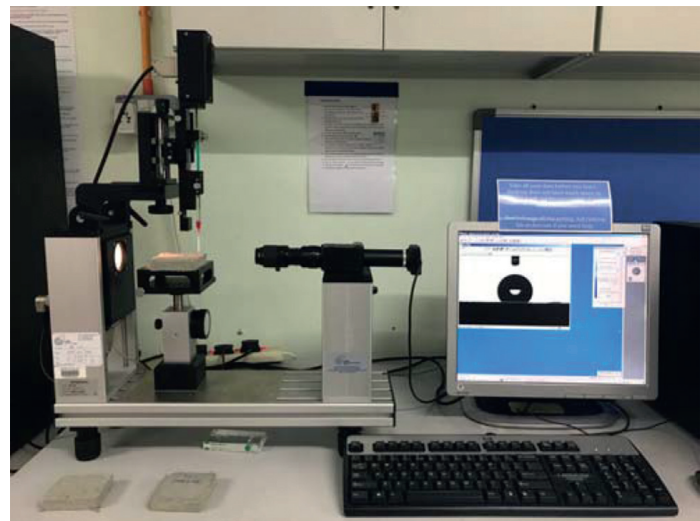

FIgURE 3: OCA 15EC with software SCA 20 module.

attaining $75.2 \%$ to $98.8 \%$ of its 28 -day compressive strength at 7 days. This could be attributed to the use of SF [20] and SBR [21], which increased the cohesiveness of the matrix. Besides that, the inclusion of $0.125-0.25 \%$ of PP fibres and $0.125 \%$ of basalt fibres had a negligible effect on the compressive strength of LCC at the early age of 7 days. Nevertheless, the maximum compressive strength of these mixes at 28 days was $15.9 \%$ higher than that of the control mix. This finding is in line with results reported by $\mathrm{Wu}$ et al. [22], where the bonding strength between matrix and fibres increased with the curing age of concrete. Moreover, the ultimate compressive strength of LCC increased by adding fibres with high modulus of elasticity. At the same fibre dosage of $0.25 \%$, LCC-basalt achieved the highest

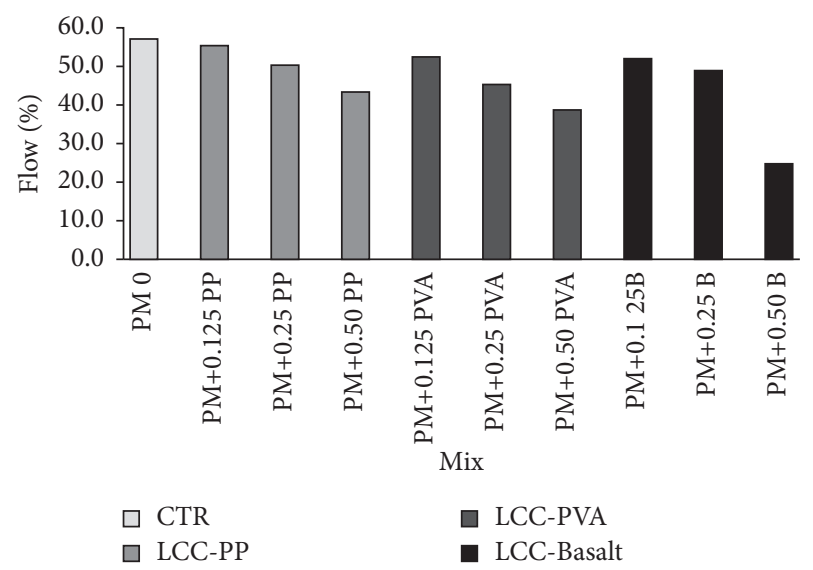

Figure 4: Flow value of LCC.

compressive strength, $15.9 \mathrm{MPa}$, followed by LCC-PVA, 13.9 MPa, and LCC-PP, 13.5 MPa.

Furthermore, the failure mechanism of LCC was improved with the use of fibres. Figure 5 shows the typical failure of LCC specimens after the compression test. For the LCC with fibres, no obvious spalling was observed. This observation indicates the effectiveness of fibres in constraining lateral deformation and reducing the brittleness of the LCC. Both LCC-PP and LCC-PVA achieved the highest compressive strength among their groups with $0.50 \%$ fibre volume. On the other hand, the addition of basalt fibres increased the compressive strength of LCC until a fibre dosage of $0.25 \%$. The compressive strength of $\mathrm{PM}+0.50 \mathrm{~B}$ 
TABLe 3: Density and compressive strength of LCC.

\begin{tabular}{lccc}
\hline Mix ID & Density $\left(\mathrm{kg} / \mathrm{m}^{3}\right)$ & \multicolumn{2}{c}{ Compressive strength $(\mathrm{MPa})$} \\
28 days \\
\hline PM-0 (control mix) & 912 & 12.0 & 12.2 \\
PM + 0.125PP & 923 & 10.9 & 13.1 \\
PM + 0.25PP & 935 & 10.0 & 13.5 \\
PM + 0.50PP & 959 & 13.9 & 14.2 \\
PM + 0.125PVA & 931 & 13.5 & 14.3 \\
PM + 0.25PVA & 939 & 13.3 & 13.9 \\
PM + 0.50PVA & 985 & 15.3 & 16.5 \\
PM + 0.125B & 940 & 10.8 & 14.1 \\
PM + 0.25B & 957 & 14.0 & 15.9 \\
PM + 0.50B & 932 & 11.6 & 14.4 \\
\hline
\end{tabular}

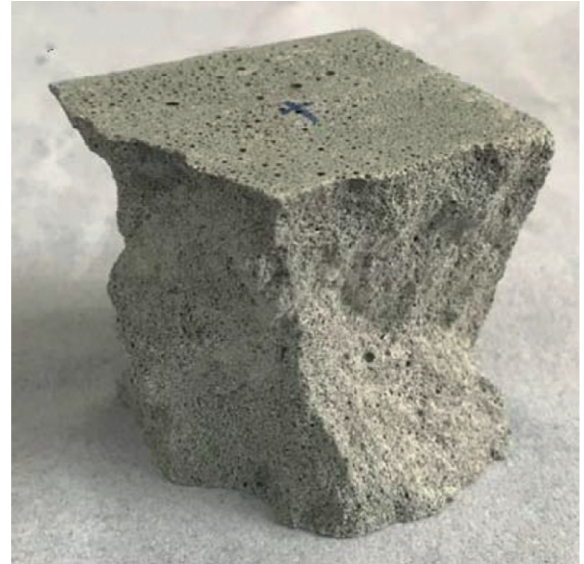

(a)

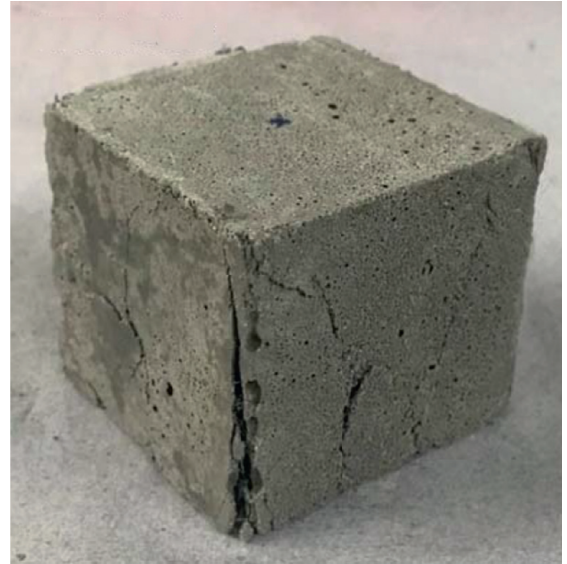

(b)

FIGURE 5: Failure pattern of LCC (a) without fibre; (b) with fibres.

was about $9.4 \%$ lower than $\mathrm{PM}+0.25 \mathrm{~B}$. This could be related to the increased formation of pores and voids within the composite due to the poor workability of $\mathrm{PM}+0.25 \mathrm{~B}$ [23]. However, the composite containing $0.50 \%$ basalt fibres still had higher strength than the composite without fibres. Thus, for PM-0, the optimum incorporation level of each fibre type was $0.50 \%$ for both PP and PVA fibres, while it was $0.25 \%$ for basalt fibres. Beyond the optimum levels, a higher SP dosage is required to achieve adequate workability.

Among all the LCC developed, PM + 0.50PVA achieved the highest compressive strength of $16.9 \mathrm{MPa}$, and this mix also fulfilled the minimum compressive strength of structural lightweight concrete recommended by CEB/RILEM [24], which is more than $15 \mathrm{MPa}$. Moreover, based on the research done by Hanif et al. [25] and Blanco et al. [26], the 28-day compressive strength of LCC produced using fly ash cenospheres was between 5 and $18 \mathrm{MPa}$ with a dry density of $885-1138 \mathrm{~kg} / \mathrm{m}^{3}$. Therefore, $\mathrm{PM}+0.50 \mathrm{PVA}$ was selected for further investigation on the effect of silane-based admixture since the 28-day compressive strength was within the reported range.

\subsubsection{Effects of Silane-Based Admixture on Compressive} Strength. The compressive strength and softening coefficient of PM $+0.50 \mathrm{PVA}$ mix with and without silane-based water repellent admixture are tabulated in Table 4 . The use of $1 \%$ and $2 \%$ water repellent admixture reduced the compressive strength of LCC by $34.0 \%$ and $26.4 \%$, respectively. This result is in line with the findings reported by Li et al. [27] and Tittarelli and Moriconi [28]. Li et al. [27] reported that the maximum reduction in compressive strength was $13.3 \%$, with the inclusion of $0.3 \%$ powder silane-based water repellent addictive. Similarly, Tittarelli and Moriconi [28] found out that $2 \%$ of silane admixture used in the form of aqueous emulsion also caused a 10-20\% reduction in compressive strength of concrete. The hydrophobic admixture may be associated with minor airentraining effect, which increased the porosity in the hardened cement mortar [16].

Softening coefficient is the ratio between the watersaturated compressive strength and dry compressive strength of a material. The purpose of determining the ability of a material to maintain its original properties when exposed to water is because the moisture content of concrete has a significant effect on the compressive strength of concrete [29], especially for low strength material. The water-saturated specimens were prepared by immersing the oven-dried specimens in water for 48 hours. The softening coefficient of PM+0.50PVA was 0.50 . With $1 \%$ and $2 \%$ of water repellent admixture, the softening coefficients of PM+0.50PVA were increased by $70 \%$ and $62 \%$, respectively. 
TABLE 4: Compressive strength, softening coefficient, and water absorption of LCC with water repellent admixture.

\begin{tabular}{lcccc}
\hline \multirow{2}{*}{ Mix ID } & \multicolumn{2}{c}{ Compressive strength (MPa) } & Softening coefficient & \multicolumn{2}{c}{ Water absorption (\%) } \\
& Dry strength & Water-saturated strength & & 30 mins \\
PM + 0.50 PVA & 16.5 & 8.3 & 0.50 & 4.1 \\
W1 PM + 0.50 PVA & 10.9 & 9.2 & 0.85 & 15.2 \\
W2 PM + 0.50 PVA & 12.1 & 9.8 & 0.81 & 3.6 \\
\hline
\end{tabular}

The PVA fibre-reinforced LCC with $1 \%$ admixture $(\mathrm{W} 1 \mathrm{PM}+0.50 \mathrm{PVA})$ can be considered as a water-resistant material since the softening coefficient exceeds 0.85 [30]. The increment in softening coefficient is attributed to the lower water absorption of LCC specimens in the presence of the silane-based water repellent admixture. Compared with $\mathrm{PM}+0.50 \mathrm{PVA}$, the 48-hour water absorption of W1PM+ $0.50 \mathrm{PVA}$ and $\mathrm{W} 2 \mathrm{PM}+0.50 \mathrm{PVA}$ was reduced by $76.3 \%$ and $74.8 \%$, respectively. Moreover, there is no significant difference between LCC performance with $1 \%$ and $2 \%$ water repellent admixture. Thus, the ideal dosage of silane-based water repellent admixture for the LCC in this research is $1 \%$.

3.4. Flexural Strength. The flexural strengths of LCCs are presented in Figure 6, while Figure 7 shows the fractured specimens after the 3-point bending test. Compared with the control specimen, all fibre-reinforced composites showed an appreciable increase in flexural strength. Theoretically, higher fibre dosage helps to sustain more load before failure, which can be observed in specimens with PVA fibres. When PVA fibres were added at $0.125 \%, 0.25 \%$, and $0.50 \%$ dosage, the flexural strength was consistently enhanced by $14.3 \%$, $25.7 \%$, and $28.6 \%$, respectively. Toutanji et al. [31] similarly reported that $0.6 \%$ PVA fibres increased the flexural strength of LCC by $25 \%$. However, PP and basalt fibres showed otherwise.

For the specimen with PP fibres, fibre dosage at 0.125\% minimally decreased the flexural strength $(-3.9 \%)$. The possible reason is that $0.125 \%$ of PP fibre dosage was insufficient to have a significant fibre bridging effect, and the low modulus of elasticity of PP fibres makes the specimen less stiff. At $0.50 \%$ dosage of PP fibres, the flexural strength of PM-0 was improved by about $10 \%$. A similar finding has been reported by $\mathrm{Wu}$ et al. [32], where incorporating $0.50 \%$ PP fibres in peach shell lightweight concrete increased the flexural strength by about $12 \%$. On the other hand, for LCCbasalt, the flexural strength decreased from $5.0 \mathrm{MPa}$ to 4.1 $\mathrm{MPa}$ at fibre dosage $0.25 \%$ and $0.50 \%$. This was most likely due to the high aspect ratio and high modulus of basalt fibres having a detrimental effect on workability, hindering the basalt fibres from distributing homogeneously [23]. Hence, this can affect the compaction of the specimen.

Among the three types of fibre, namely, the PP, PVA, and basalt fibres, the basalt fibres gave the highest improvement in flexural strength $(\mathrm{PM}+0.25 \mathrm{~B})$ followed by PVA fibres (PM+0.50PVA) and PP fibres (PM+0.50PP). This could be related to the stiffness of fibre. Basalt fibre has the highest modulus of elasticity, about 100-110 GPa; thus, it has better resistance to deformation of specimens [20]. However, the prismatic specimen of LCC-basalt broke into half after testing, as shown in Figure 7(b). This could be due to the rupture of basalt fibres since it possesses high stiffness [20]. Nevertheless, the fibres could still bridge the specimens from breaking into half in the case of LCC-PP and LCC-PVA (Figures 7(c) and 7(d)). Additionally, from Figures 8(c) and 8(d), fibres pull-out failure was observed. This shows that PP and PVA fibres could resist tensile stresses effectively. Besides that, LCC-PVA had wider crack width compared with LCC-PP. The reason is that the PVA fibres have higher tensile strength than PP fibres, thus allowing LCC-PVA to undergo greater deflection.

Furthermore, the effect of waterproofing admixture on the flexural strength of LCC was studied. The result shows that with $1 \%$ and $2 \%$ silane-based water repellent agent, the flexural strength of PM + 0.50PVA was decreased by $13.3 \%$ and $17.8 \%$, correspondingly. This further justifies the finding in the earlier section where the porosity of LCC was increased after incorporating the hydrophobic agent.

3.5. Static Water Contact Angle. The contact angles of water droplets on LCC tiles with different dosages of silane-based water repellent are presented in Figure 9. These results were used to determine the hydrophobicity of a material. When the water droplet remains on the surface in the form of a sphere, as shown in Figure 10 (hydrophobic surface), this indicates that there is no molecular attraction between water and the composite. In general, a solid surface with a water contact angle, $\theta \geq 90^{\circ}$, is considered as hydrophobic, while a solid surface with $\theta \geq 120^{\circ}$ and $\theta \leq 150^{\circ}$ is considered as over hydrophobic. On the other hand, a solid surface with $\theta$ less than or equal to $90^{\circ}$ is considered hydrophilic [33-35]. The hydrophobic properties of LCC were improved with the use of silane-based water repellent admixture. The water contact angle of W1PM + 0.50PVA and W2PM + 0.50PVA was $128.2^{\circ}$ and $109.2^{\circ}$, respectively. It was $33 \%$ and $13 \%$ higher than the corresponding mix without water repellent admixture, $\mathrm{PM}+0.50 \mathrm{PVA}$. Therefore, the surface of $\mathrm{W} 1 \mathrm{PM}+0.50 \mathrm{PVA}$ is considered as over hydrophobic, while W2PM+0.50PVA is considered as hydrophobic. The hydrophobic properties of LCC will be advantageous for industrial applications such as façade panels since surface staining can be avoided.

From the water contact angle results, $1 \%$ of silane-based water repellent is recommended, similar as described in the earlier section. It is interesting to note that even without the inclusion of silane-based water repellent admixture, the water contact angle of PM $+0.50 \mathrm{PVA}$ tile was still larger than $90^{\circ}$, which is considered hydrophobic. This result agrees well with the findings of Flores et al. [36] where the water contact angle of mortar tile was enhanced by about $26 \%$ using $1 \%$ PVA fibres. The incorporation of PVA fibres increased the 


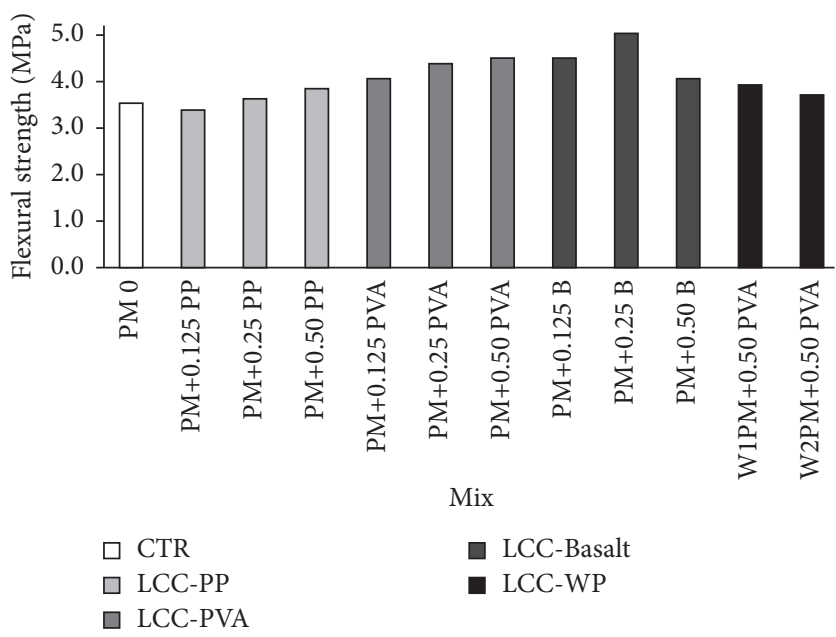

FIGURE 6: Flexural strength of LCC at 28 days.

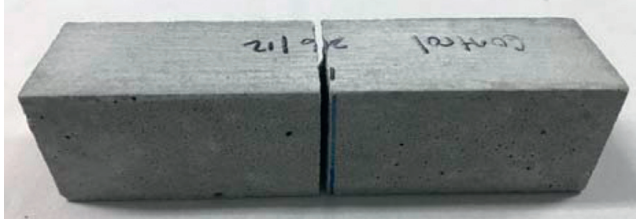

(a)

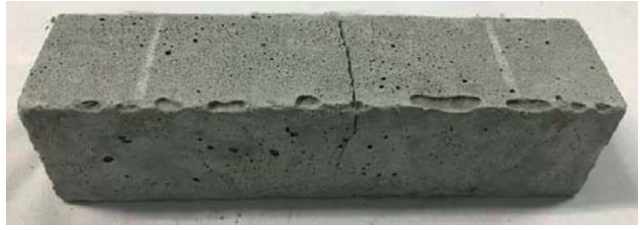

(c)

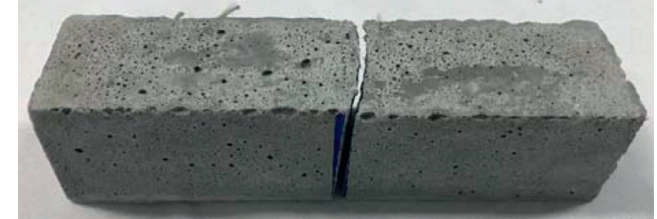

(b)

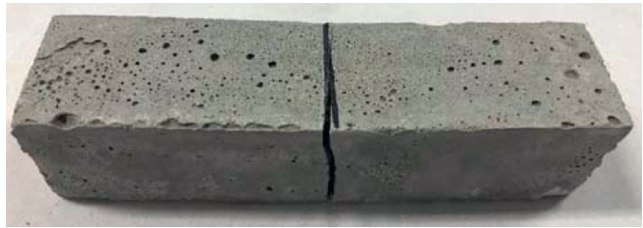

(d)

Figure 7: Fractured LCC after 3-point bending test: (a) control mix; (b) LCC-basalt; (c) LCC-PVA; (d) LCC-PP.

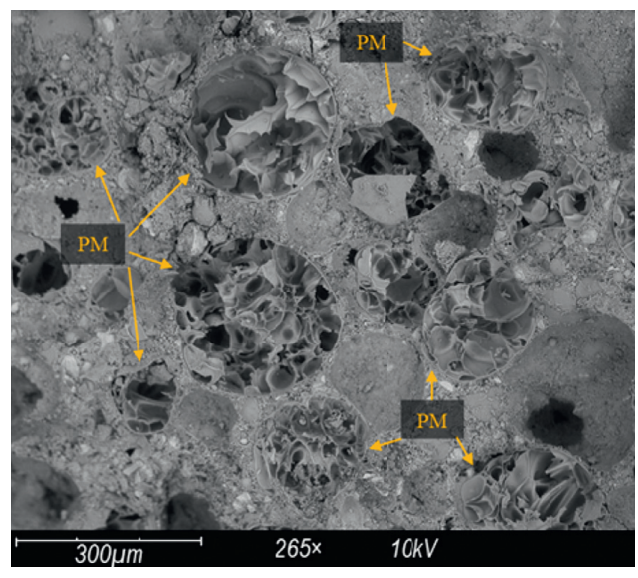

(a)

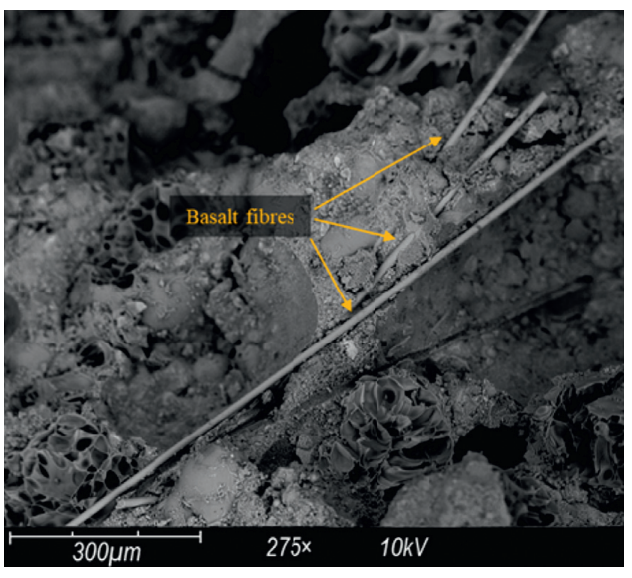

(b)

Figure 8: Continued. 


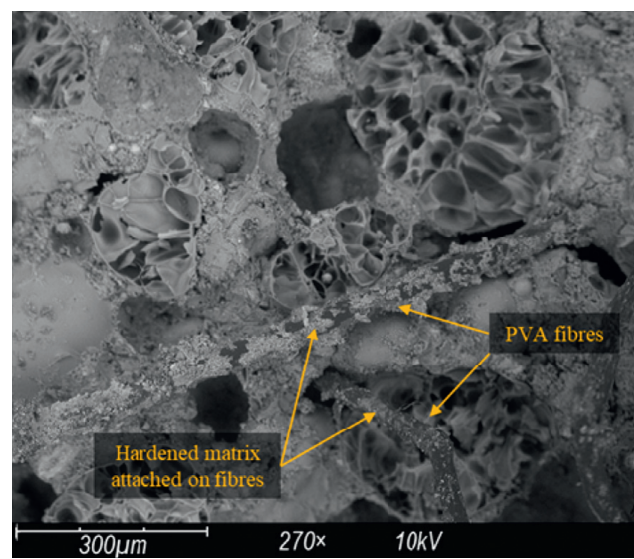

(c)

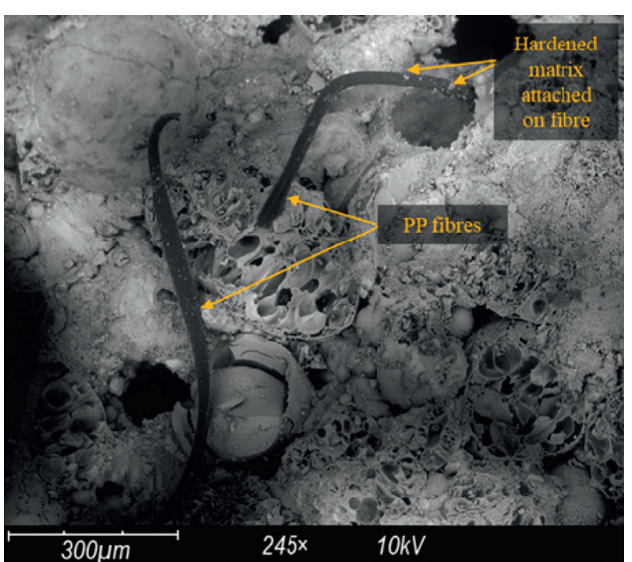

(d)

FIGURE 8: SEM images of (a) control mix; (b) LCC-basalt; (c) LCC-PVA; (d) LCC-PP.

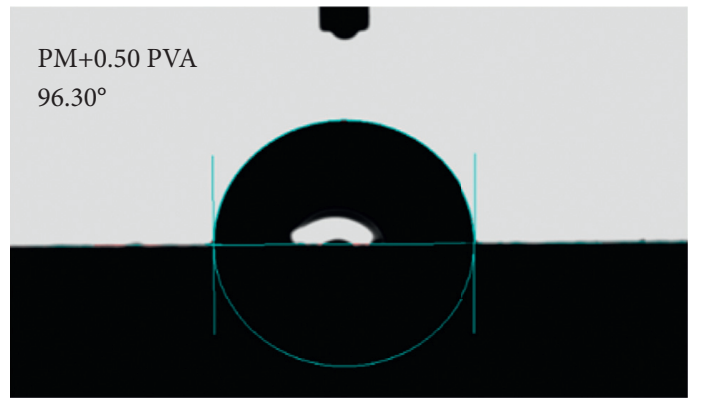

(a)

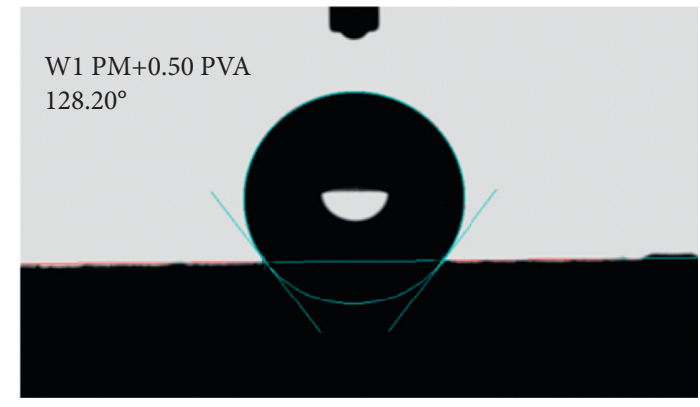

(b)

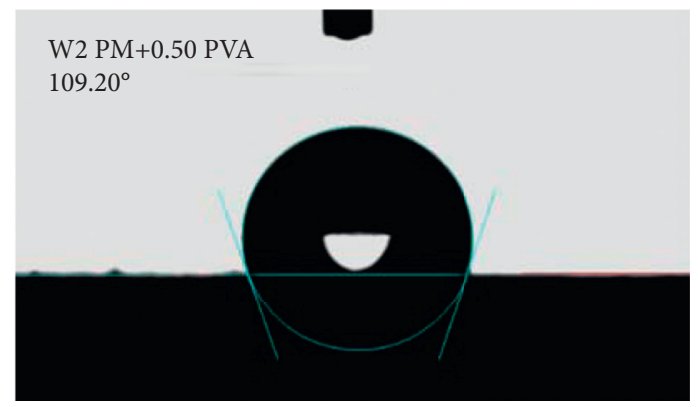

(c)

Figure 9: Water contact angle of LCC. (a) PM+0.50PVA, (b) W1 PM+0.50PVA, and (c) W2 PM+0.50PVA.

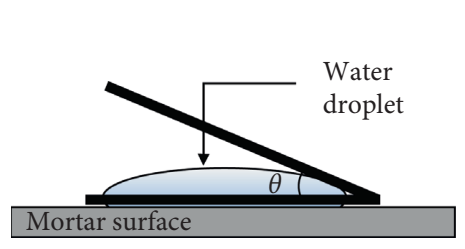

Hydrophilic surface: $0 \leq \theta \leq 90^{\circ}$

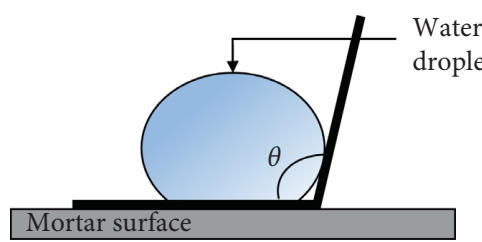

Hydrophobic surface: $90^{\circ} \leq \theta$

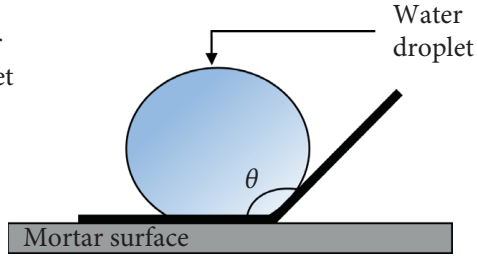

Over hydrophobic surface: $120^{\circ} \leq \theta<150^{\circ}$

FigURE 10: Range of water contact angle for hydrophilic, hydrophobic, and over hydrophobic surfaces [36]. 
surface roughness of the PM+0.50 PVA tile and consequently lowered the surface energy and enhanced the hydrophobic properties of the material.

\section{Conclusion}

In this study, the effects of fibres and silane-based water repellent admixture on fresh and hardened properties of LCC were investigated. Based on the experimental results, the following conclusions can be drawn:

(i) The workability of LCC decreased with the increasing fibre dosage. LCC with $0.5 \%$ basalt fibre experienced the highest reduction in workability as basalt fibre has a higher modulus of elasticity and aspect ratio than the PP and PVA fibres.

(ii) The dry density of LCC developed was in the range of $912-985 \mathrm{~kg} / \mathrm{m}^{3}$.

(iii) The failure mechanism of LCC was improved with the use of fibres. The PP, PVA, and basalt fibres are effective in constraining lateral deformation and reducing the brittleness of LCC.

(iv) An optimised amount of fibre is crucial in improving the mechanical strength of LCC. The ideal $\mathrm{PP}, \mathrm{PVA}$, and basalt fibre dosage in this study is $0.5 \%, 0.5 \%$, and $0.25 \%$, respectively. Among all the mixes, LCC with $0.5 \%$ PVA fibre achieved the highest compressive strength of $16.5 \mathrm{MPa}$.

(v) The addition of fibre into LCC increased the flexural strength by $3.9 \%$ to $43.5 \%$. The highest flexural strength achieved was $5.0 \mathrm{MPa}$ when $0.25 \%$ basalt fibre was incorporated.

(vi) Although silane-based water repellent admixture reduced the compressive and flexural strengths of LCC, it has an excellent effect in reducing the water absorption of LCC. The ideal dosage of silane-based water repellent admixture for the LCC is $1 \%$.

(vii) With $1 \%$ silane-based water repellent admixture and 0.5\% PVA fibre, W1PM + 0.50PVA exhibited a softening coefficient of 0.85 and a water contact angle of $128.20^{\circ}$. Hence, W1PM +0.50 PVA has the potential to be used in the fabrication of façade panels due to its adequate strength and hydrophobic properties.

\section{Data Availability}

The data used to support the findings of this study are available from the corresponding author upon request.

\section{Conflicts of Interest}

The authors declare that they have no conflicts of interest.

\section{Acknowledgments}

The authors are grateful for the financial support provided by Ministry of Higher Education, Malaysia, under the funding FP056-2018A (FRGS/1/2018/TK06/UM/02/1).

\section{References}

[1] M. Jedidi, O. Benjeddou, and c. soussi, "Effect of expanded perlite aggregate dosage on properties of lightweight concrete," Jordan Journal of Civil Engineering, vol. 9, pp. 278-291, 2015.

[2] O. Sengul, S. Azizi, F. Karaosmanoglu, and M. A. Tasdemir, "Effect of expanded perlite on the mechanical properties and thermal conductivity of lightweight concrete," Energy and Buildings, vol. 43, no. 2-3, pp. 671-676, 2011.

[3] M. Ibrahim, A. Ahmad, M. S. Barry, L. M. Alhems, and A. C. Mohamed Suhoothi, "Durability of structural lightweight concrete containing expanded perlite aggregate," International Journal of Concrete Structures and Materials, vol. 14, no. 1, p. 50, 2020.

[4] A. G. Celik, A. M. Kilic, and G. O. Cakal, "Expanded perlite aggregate characterization for use as a lightweight construction raw material," Physicochemiacal Problems Mineral Proceesing, vol. 49, no. 2, pp. 689-700, 2013.

[5] P. M. Angelopoulos, M. Taxiarchou, and I. Paspaliaris, "Production of durable expanded perlite microspheres in a Vertical Electrical Furnace," IOP Conference Series: Materials Science and Engineering, vol. 123, Article ID 012061, 2016.

[6] K. Sodeyama, Y. Sakka, Y. Kamino, and H. Seki, "Preparation of fine expanded perlite," Journal of Materials Science, vol. 34, no. 10, pp. 2461-2468, 1999.

[7] Q. Jing, L. Fang, H. Liu, and P. Liu, "Preparation of surfacevitrified micron sphere using perlite from Xinyang, China," Applied Clay Science, 2011.

[8] G. W. Leong, K. H. Mo, Z. P. Loh, and Z. Ibrahim, "Mechanical properties and drying shrinkage of lightweight cementitious composite incorporating perlite microspheres and polypropylene fibers," Construction and Building Materials, vol. 246, 2020.

[9] L. Kidalova, N. Stevulova, E. Terpakova, and A. Sicakova, "Utilization of alternative materials in lightweight composites," Journal of Cleaner Production, vol. 34, pp. 116-119, 2012.

[10] N. Banthia and R. Gupta, "Hybrid fiber reinforced concrete (HyFRC): fiber synergy in high strength matrices," Materials and Structures, vol. 37, no. 10, pp. 707-716, 2004.

[11] Z. Dong, M. Deng, C. Zhang, Y. Zhang, and H. Sun, “Tensile behavior of glass textile reinforced mortar (TRM) added with short PVA fibers," Construction and Building Materials, vol. 260, Article ID 119897, 2020.

[12] Y. Du, M. Zhang, F. Zhou, and D. Zhu, "Experimental study on basalt textile reinforced concrete under uniaxial tensile loading," Construction and Building Materials, vol. 138, pp. 88-100, 2017.

[13] Y. Qin, X. Zhang, J. Chai, Z. Xu, and S. Li, "Experimental study of compressive behavior of polypropylene-fiber-reinforced and polypropylene-fiber-fabric-reinforced concrete," Construction and Building Materials, vol. 194, pp. 216-225, 2019.

[14] M. Y. L. Chew and P. P. Tan, "Facade staining arising from design features," Construction and Building Materials, vol. 17, no. 3, pp. 181-187, 2003.

[15] Y. Xu and D. D. L. Chung, "Cement of high specific heat and high thermal conductivity, obtained by using silane and silica fume as admixtures," Cement and Concrete Research, vol. 30, no. 7, pp. 1175-1178, 2000.

[16] B. Yan, F. Ren, M. Cai, and C. Qiao, "Influence of new hydrophobic agent on the mechanical properties of modified cemented paste backfill," Journal of Materials Research and Technology, vol. 8, no. 6, pp. 5716-5727, 2019. 
[17] K. Xu, S. Ren, J. Song et al., "Colorful superhydrophobic concrete coating," Chemical Engineering Journal, vol. 403, Article ID 126348, 2021.

[18] C. Chen, Y. Wang, G. Pan, and Q. Wang, "Gel-sol synthesis of surface-treated $\mathrm{TiO} 2$ nanoparticles and incorporation with waterborne acrylic resin systems for clear UV protective coatings," Journal of Coatings Technology and Research, vol. 11, no. 5, pp. 785-791, 2014.

[19] C. H. Jiang, S. S. Huang, Y. W. Zhu, Y. F. Lin, and D. Chen, "Effect of polypropylene and basalt fiber on the behavior of mortars for repair applications," Annals of Materials Science \& Engineering, 2016.

[20] Z. P. Loh, K. H. Mo, C. G. Tan, and S. H. Yeo, "Mechanical characteristics and flexural behaviour of fibre-reinforced cementitious composite containing PVA and basalt fibres," Sādhanā, vol. 44, no. 4, p. 98, 2019.

[21] Y. Ohama, "Polymer-based admixtures," Cement and Concrete Composites, vol. 20, no. 2, pp. 189-212, 1998.

[22] T. Wu, X. Yang, H. Wei, and X. Liu, "Mechanical properties and microstructure of lightweight aggregate concrete with and without fibers," Construction and Building Materials, vol. 199, pp. 526-539, 2019.

[23] C. Jiang, K. Fan, F. Wu, and D. Chen, "Experimental study on the mechanical properties and microstructure of chopped basalt fibre reinforced concrete," Materials \& Design, vol. 58, pp. 187-193, 2014.

[24] CEB, Functional Classification of Lightweight Concrete, Recommendations LC2, RILEM Publications SARL, Stuttgart, Germany, 2nd edition, 1978.

[25] A. Hanif, Z. Lu, Y. Cheng, S. Diao, and Z. Li, "Effects of different lightweight functional fillers for use in cementitious composites," International Journal of Concrete Structures and Materials, vol. 11, no. 1, pp. 99-113, 2017.

[26] F. Blanco, P. Garćia, P. Mateos, and J. Ayala, "Characteristics and properties of lightweight concrete manufactured with cenospheres," Cement and Concrete Research, vol. 30, no. 11, pp. 1715-1722, 2000.

[27] H. Li, C. Xu, B. Dong, Q. Chen, L. Gu, and X. Yang, "Enhanced performances of cement and powder silane based waterproof mortar modified by nucleation C-S-H seed," Construction and Building Materials, vol. 246, Article ID 118511, 2020.

[28] F. Tittarelli and G. Moriconi, "The effect of silane-based hydrophobic admixture on corrosion of reinforcing steel in concrete," Cement and Concrete Research, vol. 38, no. 11, pp. 1354-1357, 2008.

[29] J. Shen and Q. Xu, "Effect of moisture content and porosity on compressive strength of concrete during drying at $105{ }^{\circ} \mathrm{C}$," Construction and Building Materials, vol. 195, pp. 19-27, 2019.

[30] T.-C. Ling, K. H. Mo, L. Qu, J. Yang, and L. Guo, "Mechanical strength and durability performance of autoclaved lime-saline soil brick," Construction and Building Materials, vol. 146, pp. 403-409, 2017.

[31] H. Toutanji, B. Xu, J. Gilbert, and T. Lavin, "Properties of poly(vinyl alcohol) fiber reinforced high-performance organic aggregate cementitious material: converting brittle to plastic," Construction and Building Materials, vol. 24, no. 1, pp. 1-10, 2010.

[32] F. Wu, C. Liu, Z. Diao et al., "Improvement of mechanical properties in polypropylene- and glass-fibre-reinforced peach shell lightweight concrete," Annals of Materials Science \& Engineering, vol. 2018, p. 11, 2018.

[33] S. Muzenski, I. Flores-Vivian, and K. Sobolev, "Hydrophobic engineered cementitious composites for highway applications," Cement and Concrete Composites, vol. 57, pp. $68-74,2015$.

[34] L. Yao and J. He, "Recent progress in antireflection and selfcleaning technology - from surface engineering to functional surfaces," Progress in Materials Science, vol. 61, pp. 94-143, 2014.

[35] S. Karthick, D.-J. Park, Y. S. Lee et al., "Development of waterrepellent cement mortar using silane enriched with nanomaterials," Progress in Organic Coatings, vol. 125, pp. 48-60, 2018.

[36] I. Flores Vivian, V. Hejazi, M. Kozhukhova, M. Nosonovsky, and K. Sobolev, "Self-assembling particle-siloxane coatings for superhydrophobic concrete," ACS Applied Materials and Interfaces, vol. 5, 2013. 